\title{
Molecular confirmation of infectious spleen and kidney necrosis virus (ISKNV) in farmed and imported ornamental fish in Australia
}

\author{
Peter G. Mohr*, Nicholas J. G. Moody, Lynette M. Williams, John Hoad, \\ David M. Cummins, Kelly R. Davies, Mark StJ. Crane
}

CSIRO Australian Animal Health Laboratory, Geelong, Victoria 3220, Australia

\begin{abstract}
Viruses of the genus Megalocytivirus have not been detected in wild populations of fish in Australia but circulate in imported ornamental fish. In 2012, detection of a megalocytivirus in healthy platys Xiphophorus maculatus was reported from a farm in Australia during surveillance testing as part of a research project undertaken at the University of Sydney. Confirmatory testing of the original samples at the AAHL Fish Diseases Laboratory verified the presence of an infectious spleen and kidney necrosis virus (ISKNV)-like virus. Additional sampling at the positive farm confirmed the persistence of the virus in the platys, with 39 of $265(14.7 \%)$ samples testing positive. Comparison of 3 separate gene regions of the virus with those of ISKNV confirmed the detection of a virus indistinguishable from ISKNV. Subsequently, ISKNV was also detected in a range of imported ornamental fish from several countries between 2013 and 2014, by screening with real-time PCR and confirmation by conventional PCR and sequence analysis. Accordingly, the current importation of live ornamental fish acts as a potential perpetual source for the establishment of ISKNV viruses within Australia. The testing of the farmed and imported ornamental fish verified the utility of the probe-based real-time PCR assay for screening of ornamental fish for Megalocytivirus.
\end{abstract}

KEY WORDS: Megalocytivirus · ISKNV · Ornamental fish $\cdot$ Real-time PCR $\cdot$ Xiphophorus maculatus Resale or republication not permitted without written consent of the publisher

\section{INTRODUCTION}

Megalocytivirus is the newest of 5 genera within the Iridoviridae family of large, enveloped, doublestranded DNA viruses (Jancovich et al. 2012). Since their discovery in the early 1990s, megalocytiviruses have caused significant disease and economic losses in marine and freshwater fish culture, predominantly in Asia. Based on major capsid protein (MCP) and ATPase gene phylogenetic analyses, the genus can be divided into 3 clusters represented by red sea bream iridovirus (RSIV), infectious spleen and kidney necrosis virus (ISKNV) and turbot reddish body iridovirus (TRBIV) (Kurita \& Nakajima 2012). Due to the significant mortalities caused in a wide range of fish species by RSIV and ISKNV, red sea bream iri- doviral disease (RSIVD) is listed in the OIE Aquatic Animal Health Code (OIE 2014a), and diagnostic methods are provided in the OIE Manual of Diagnostic Tests for Aquatic Animals (OIE 2014b).

The international trade of live ornamental fish (both freshwater and marine) has been demonstrated as a potential source of megalocytiviruses, and in particular ISKNV-like virus, spread (Whittington \& Chong 2007, Jeong et al. 2008). For example, freshwater African lampeye Aplocheilichthys normani and dwarf gourami Colisa lalia imported into Japan were infected with the ISKNV-like viruses, African lampeye iridovirus (ALIV) and dwarf gourami iridovirus (DGIV), respectively (Sudthongkong et al. 2002). Freshwater paradise fish Macropodus opercularis imported into South Korea have died due to infection with an ISKNV-like virus 
(Kim et al. 2010). Banggai cardinalfish iridovirus (BCIV) is an ISKNV-like virus that was isolated from marine Banggai cardinalfish Pterapogon kauderni imported into the US (Weber et al. 2009). In addition, marine orbiculate batfish Platax orbicularis imported to Belgium were found to be infected with a virus identical to BCIV (Sriwanayos et al. 2013).

Although megalocytiviruses do not occur in wild populations of fish in Australia, several ISKNV-like viruses are known to circulate in imported ornamental fish and have caused disease in a native species on 1 occasion. A retrospective study of diseased farmed Murray cod Maccullochella peelii peelii from Victoria in 2003 identified an ISKNV-like virus, Murray cod iridovirus (MCIV) (Go et al. 2006). The route of introduction of the virus into the farm was not determined. The same study also identified DGIV in dwarf gourami that had been imported to Australia and died in commercial aquaria. Subsequently, a range of gourami species imported in 2011 from several countries were found to contain DGIV within both quarantine and post-quarantine facilities (Becker et al. 2013). Furthermore, surveillance of a range of ornamental fish species imported to Australia from several countries between 2012 and 2013 with high mortalities in quarantine were found to be infected with an ISKNV-like virus (Nolan et al. 2015).

Most recently, DGIV was detected at an Australian ornamental fish farm that was breeding exotic species of ornamental fish (Becker et al. 2013). This finding suggested that the virus had become established post-quarantine, and samples were therefore submitted to our laboratory for confirmatory testing. In this study, we describe the molecular assays that were used to confirm the presence and later the persistence of an ISKNV virus within platys Xiphophorus maculatus at the farm. In addition, we detail the continued detection of ISKNV viruses in ornamental fish imported to Australia between 2013 and 2014.

\section{MATERIALS AND METHODS}

\section{Tissues and nucleic acid extraction}

In total, 3 diagnostic submissions were investigated. In 2012, 4 tissue homogenates (pooled kidney, liver and spleen) from platys Xiphophorus maculatus at an Australian ornamental fish farm were submitted by the University of Sydney to the CSIRO Australian Animal Health Laboratory - Fish Diseases Laboratory (AFDL) for confirmation of infection with ISKNV-like megalocytivirus (Samples A1-A4). The samples were collected from clinically normal fish during a research project to investigate the incidence of megalocytivirus in ornamental fish species (Becker et al. 2013). In response to the initial detection and confirmation of ISKNV, frozen tissues from a further 265 platys from 17 individual batches on the same property were submitted by the Queensland Government, Department of Agriculture, Fisheries and Forestry to determine the distribution of the ISKNV-like virus (Samples B1-B265). In addition, during 2013 and 2014, trials by the Australian Government, Department of Agriculture (AGDoA) were conducted to monitor the health of live ornamental fish being imported into Australia from a range of Asian countries. As part of the trial, 272 ethanol-fixed tissues from randomly selected consignments were collected during on-arrival visual inspection and submitted to AFDL by the AGDoA to investigate the incidence of megalocytivirus (Samples C1-C272). The sampled consignments included over 20 species of ornamental fish from several genera including Xiphophorus, Colisa, Poecilia, Pterophytllum, Trichogaster and Astronotus.

For the initial submission (A1-A4), using the QIAamp viral RNA mini kit (Qiagen) total nucleic acid was extracted from $140 \mu \mathrm{l}$ of the 4 tissue homogenates submitted for confirmatory testing. The further frozen tissues (B1-B265) from the 17 individual batches on the ornamental fish farm were thawed and the viscera of each fish fixed individually in ethanol $(80 \% \mathrm{v} / \mathrm{v})$ and processed as described below. The ethanol-fixed fish from the imported ornamental fish health trial (C1-C272) were dissected individually, and the kidney and spleen or viscera (dependent on size) were sampled. The dissected tissues, derived from samples of either the 17 individual batches of the ornamental fish farm or the imported ornamental fish health trial, were subsequently homogenized in phosphate-buffered saline (PBS) using a FastPrep-24 bead-beater (MP Biomedicals). The homogenates were clarified by centrifugation at $10000 \times g$ ( $5 \mathrm{~min}$ ), and total nucleic acid extracted from $50 \mu \mathrm{l}$ of the supernatant using the MagMAX-96 ${ }^{\mathrm{TM}}$ Viral RNA Isolation Kit on a MagMAX ${ }^{\mathrm{TM}}$ Express-96 Deep Well Magnetic Particle Processor (Life Technologies), and nucleic acid was eluted in $50 \mu$ lelution buffer.

\section{Molecular detection and sequence analysis}

The Megalocytivirus TaqMan qPCR, based on a SYBR Green method (Caipang et al. 2003), was developed for the detection of RSIV but has also been shown to detect ISKNV-like viral nucleic acid in our laboratory. All samples were initially screened by this Megalocytivirus TaqMan qPCR (Table 1) that is 


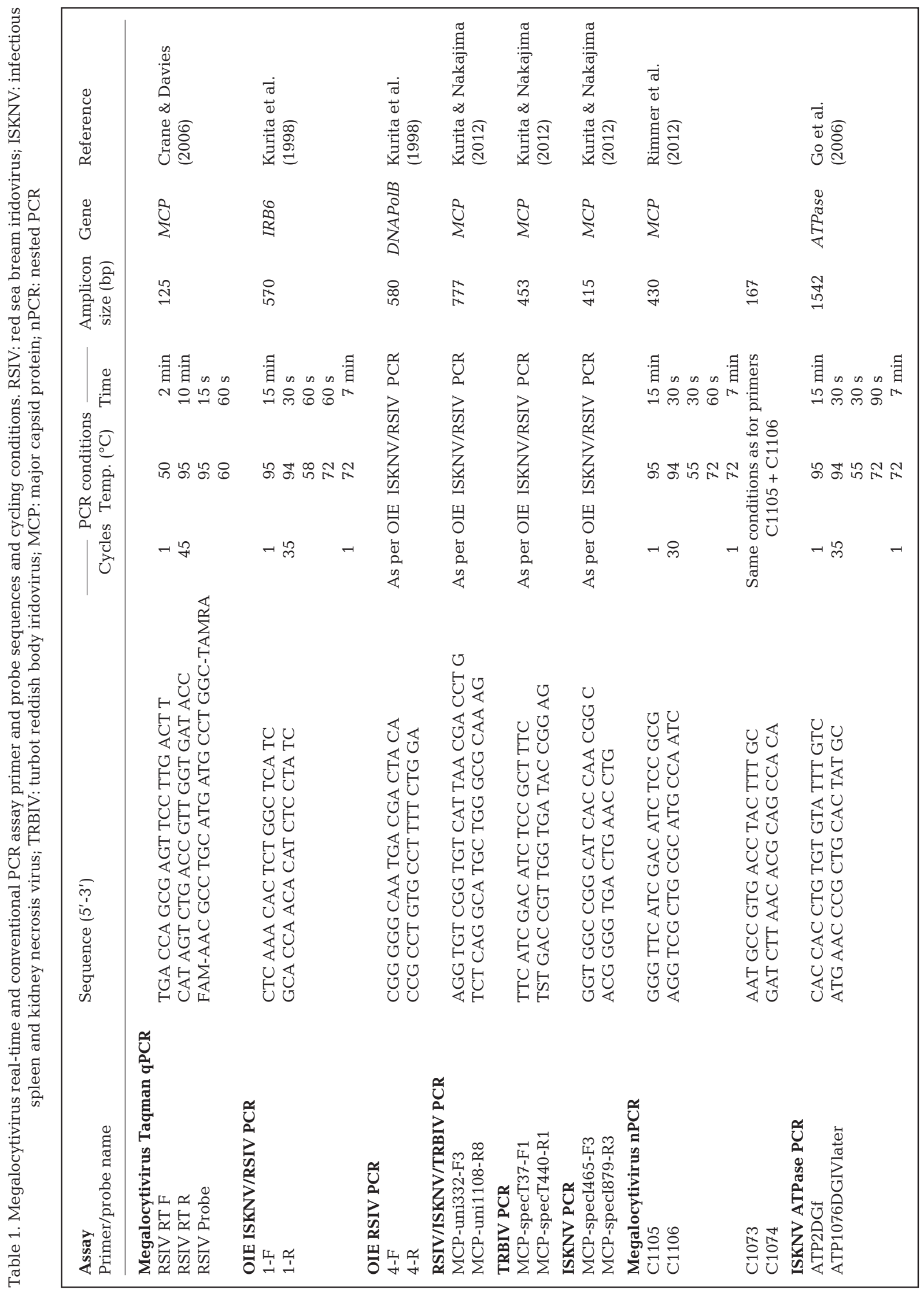


multiplexed with primers and probe specific for $18 \mathrm{~S}$ ribosomal RNA (Applied Biosystems) to validate the nucleic acid extraction procedure. Each $25 \mu \mathrm{lPCR}$ mixture contained $2 \mu \mathrm{l}$ extracted nucleic acid template, $12.5 \mu \mathrm{l}$ TaqMan Universal PCR Master Mix (Life Technologies) and a final concentration of $900 \mathrm{nM}$ for each megalocytivirus primer, $250 \mathrm{nM}$ for the probe and $100 \mathrm{nM}$ for each $18 \mathrm{~S}$ primer and probe. The qPCR assays were performed in a 7500 Fast Real-Time PCR System (Life Technologies) and analysed with the 7500 software. Samples were tested in duplicate and to be classified as positive must have generated typical amplification curves that crossed a 0.1 threshold within 45 cycles. An RSIV-positive control and a no-template control were included in each assay plate.

Positive qPCR samples were subsequently confirmed by conventional OIE RSIV/ISKNV and OIE RSIV PCR (OIE 2014b). In addition, more recently published conventional assays designed to detect and differentiate viruses of the Megalocytivirus genus (Kurita \& Nakajima 2012) and a nested PCR designed to detect all megalocytiviruses (Rimmer et al. 2012) were used (Table 1). For conventional PCR assays, $2 \mu \mathrm{l}$ extracted nucleic acid template was added to $23 \mu \mathrm{l}$ reaction mix containing $12.5 \mu \mathrm{l}$ HotStarTaq Master Mix (Qiagen), $360 \mathrm{nM}$ of each primer and molecular grade water. The nested PCR had $2 \mu \mathrm{l}$ primary PCR added to a $23 \mu \mathrm{l}$ reaction mix containing $12.5 \mu \mathrm{l}$ HotStarTaq Master Mix (Qiagen), $360 \mathrm{nM}$ of each primer and molecular grade water. An RSIVpositive control and a no-template control were included in each conventional assay run.

Amplicons for all conventional assays were visualised after electrophoresis on $1.5 \%$ agarose gels stained with SYBR Safe DNA Gel Stain (Life Technologies). Amplicons of the expected size were excised from the gel and purified using the QIAquick Gel Extraction Kit (Qiagen). Each amplicon was sequenced using forward and reverse primers by direct product sequencing using the BigDye Terminator v3.1 Cycle Sequencing chemistry and 3130xl Genetic
Analyzer (Applied Biosystems). Chromatogram analysis, consensus sequence generation, BlastN searches of the NCBI database and multiple sequence alignments were conducted using Geneious Pro (Biomatters) and phylogenetic analyses using the neighbourjoining method with a bootstrap consensus tree being inferred from 10000 replicates were undertaken using MEGA5 (Tamura et al. 2011). Evolutionary distances were calculated using the Tamura-Nei model method. All amplicons sequenced were submitted to GenBank (see the Appendix).

\section{RESULTS}

All 4 tissue homogenates of the platys originating from the Australian ornamental fish farm and submitted to the AFDL tested positive by the megalocytivirus TaqMan qPCR (Table 2). Only Sample A2, with a threshold cycle number $\left(C_{\mathrm{T}}\right)$ of 28 , was also positive by the OIE RSIV/ISKNV PCR, RSIV/ISKNV/ TRBIV PCR and ISKNV PCR. The megalocytivirus nested PCR with a further round of PCR detected 2 additional qPCR-positive samples, A1 and A3, with $C_{\mathrm{T}}$ values of 32.4 and 32.8 , respectively. As expected, the RSIV-specific OIE RSIV PCR and TRBIV-specific OIE TRBIV PCR produced negative results for all samples. Since the RSIV/ISKNV/TRBIV PCR includes the $M C P$ region targeted by the ISKNV PCR and has a larger amplicon than the nested PCR MCP target (777 bp compared to $167 \mathrm{bp}$ ), the A2 amplicon from the RSIV/ISKNV/TRBIV PCR was sequenced. The sequence was identical to an ISKNV reference (AF371960) and had nucleotide identities of 93.8 and 93.6\% to RSIV (AB104413) and TRBIV (GQ273492) references, respectively (Fig. 1a). The A2 amplicon from the OIE RSIV/ISKNV PCR (570 bp) for the IRB6 genome region was also identical to the ISKNV reference (Fig. 1b). The analysis confirmed the submitted Megalocytivirus species was ISKNV.

All subsequent surveillance samples (B1-B265), comprising 265 platys from 17 different batches,

Table 2. Megalocytivirus TaqMan qPCR, conventional and nested PCR (nPCR) assays performed on initial platy Xiphophorus maculatus samples submitted for ISKNV-like virus confirmation. +: positive, -: negative. Values shown are cycle threshold numbers

\begin{tabular}{|lccccccc|}
\hline Sample & $\begin{array}{c}\text { Megalocytivirus } \\
\text { TaqMan qPCR }\end{array}$ & $\begin{array}{c}\text { OIE ISKNV/ } \\
\text { RSIV PCR }\end{array}$ & $\begin{array}{c}\text { OIE RSIV } \\
\text { PCR }\end{array}$ & $\begin{array}{c}\text { RSIV/ISKNV/ } \\
\text { TRBIV PCR }\end{array}$ & $\begin{array}{c}\text { TRBIV } \\
\text { PCR }\end{array}$ & $\begin{array}{c}\text { ISKNV } \\
\text { PCR }\end{array}$ & $\begin{array}{c}\text { Megalocytivirus } \\
\text { nPCR }\end{array}$ \\
\hline A1 & 32.4 & - & - & - & - & - & + \\
A2 & 28.3 & + & - & - & - & + & + \\
A3 & 32.8 & - & - & - & - & - & - \\
A4 & 39.7 & - & - & - & - & - \\
\hline
\end{tabular}



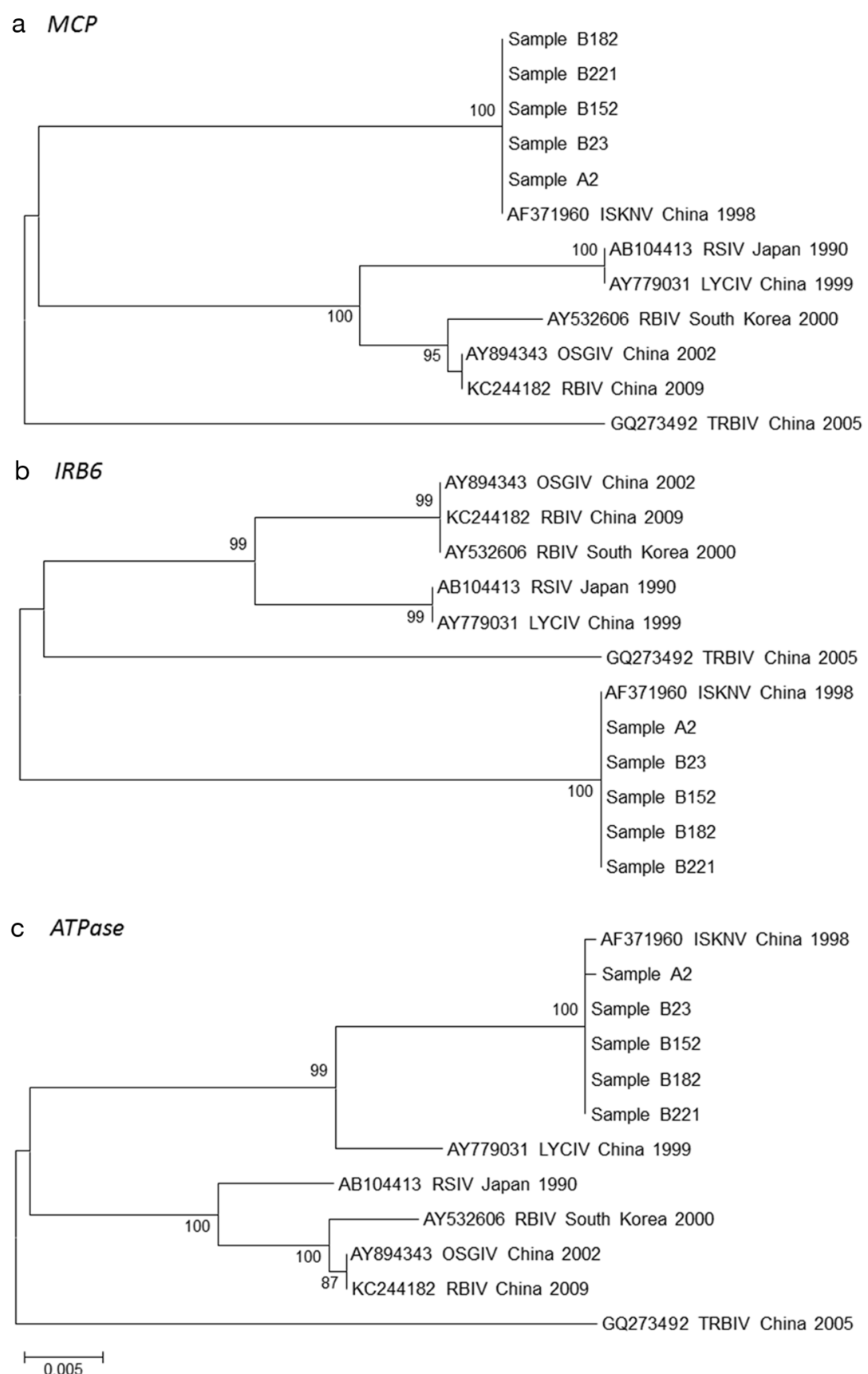

Fig. 1. Neighbour-joining phylogenetic trees based on (a) 720 bp nucleotide sequences of the MCP (RSIV/ISKNV/TRBIV PCR), (b) 524 bp nucleotide sequences of the IRB6 (OIE ISKNV/RSIV PCR) and (c) $1437 \mathrm{bp}$ nucleotide sequences of the ATPase region (ISKNV ATPase PCR) of platy Xiphophorus maculatus sample sequences compared with reference megalocytivirus complete genome sequences obtained from GenBank. The percentages of replicate trees in which the associated taxa clustered together in the bootstrap test (10000 replicates) are shown next to the branches

were individually screened with the megalocytivirus Taqman qPCR, and 39 fish $\left(C_{\mathrm{T}} 27.6\right.$ to 43.5$)$ from 12 different batches produced positive results (Table 3 ).
Of these TaqMan-positive samples, 22 were positive by the OIE RSIV/ ISKNV PCR and 24 by RSIV/ISKNV/ TRBIV PCR, whereas 34 were positive using the megalocytivirus nested PCR. The sensitivity of the 3 assays varied; of the 18 samples with $C_{\mathrm{T}}$ values less than 35 , only 1 (B177) was negative by the OIE RSIV/ ISKNV PCR. The samples with the highest qPCR $C_{\mathrm{T}}$ values that were detected by each assay were B233 $\left(C_{\mathrm{T}}=38.6\right), \mathrm{B} 50\left(C_{\mathrm{T}}=40.3\right)$ and $\mathrm{B} 61$ $\left(C_{\mathrm{T}}=41.8\right)$ for the OIE RSIV/ISKNV PCR, RSIV/ISKNV/TRBIV PCR and megalocytivirus nested $\mathrm{PCR}$, respectively.

The OIE RSIV/ISKNV PCR and RSIV/ISKNV/TRBIV PCR both generated positive amplicons from 10 different batches. The amplicons, generated from samples B23, B152, B182 and B221, for each assay were sequenced. The 4 sequences for the 2 different genome regions were identical to those for A2 and ISKNV. This confirmed the continued presence of ISKNV on the surveyed property. BLAST analysis revealed that the ISKNV phylogenetic cluster of megalocytiviruses contained viruses with identical MCP gene regions, i.e. ISKNV, DGIV and MCIV. DGIV and MCIV were also identical with ISKNV in the IRB 6 gene region encompassed by the assay. To generate additional data for comparison with ISKNV, a third 1436 bp ATPase region (ISKNV ATPase PCR) was amplified, sequenced and analysed from A2, B23, B152, B182 and B221 (Fig. 1C). The 4 surveillance samples had 1 nucleotide difference to ISKNV but were identical to MCIV and DGIV by BLAST. Sample A2 from the initial submission had 1 additional nucleotide change not present in ISKNV, MCIV or DGIV.

Trials to monitor the health status of live ornamental fish being imported into Australia were conducted in 2013 and 2014 . Of the 272 randomly selected fish, $7 \%$ (19) from 5 different genera, Colisa, Poecilia, Pterophyllum, 
Table 3. Megalocytivirus TaqMan PCR-positive surveillance samples and subsequent conventional PCR testing. +: positive, -: negative. Values shown are cycle threshold numbers

\begin{tabular}{|lccccc|}
\hline Sample & Batch & Megalo- & OIE & RSIV/ & Megalo- \\
& & cytivirus & RSIV/ & ISKNV/ & cytivirus \\
& & TaqMan & ISKNV & TRBIV & nPCR \\
& & qPCR & PCR & PCR & \\
\hline B8 & 1 & 38.4 & - & - & + \\
B23 & 3 & 30.4 & + & + & + \\
B24 & 3 & 35.3 & - & - & + \\
B25 & 3 & 40.1 & - & - & + \\
B26 & 3 & 39.1 & - & - & - \\
B28 & 3 & 30.7 & + & + & + \\
B36 & 4 & 38.1 & - & - & + \\
B37 & 4 & 36.6 & + & + & + \\
B41 & 4 & 41.6 & - & - & + \\
B48 & 5 & 40.2 & - & - & + \\
B50 & 5 & 40.3 & - & + & + \\
B52 & 5 & 29.7 & + & + & + \\
B61 & 5 & 41.8 & - & - & + \\
B67 & 6 & 33.6 & + & + & + \\
B74 & 6 & 35.4 & + & + & + \\
B84 & 7 & 32.0 & + & + & + \\
B98 & 8 & 40.3 & - & - & - \\
B101 & 8 & 30.6 & + & + & + \\
B102 & 8 & 38.0 & - & + & + \\
B111 & 8 & 36.8 & - & + & + \\
B121 & 9 & 41.4 & - & - & - \\
B122 & 9 & 31.2 & + & + & + \\
B124 & 9 & 30.2 & + & + & + \\
B152 & 11 & 27.6 & + & + & + \\
B166 & 11 & 32.6 & + & + & + \\
B167 & 12 & 31.7 & + & + & + \\
B170 & 12 & 37.7 & + & - & + \\
B172 & 12 & 38.0 & - & - & + \\
B173 & 12 & 30.7 & + & + & + \\
B174 & 12 & 38.3 & + & - & + \\
B177 & 12 & 29.8 & - & + & + \\
B178 & 12 & 33.8 & + & + & + \\
B180 & 12 & 34.4 & + & + & + \\
B182 & 12 & 29.6 & + & + & + \\
B183 & 12 & 31.7 & + & + & + \\
B221 & 15 & 30.1 & + & + & + \\
B222 & 15 & 43.5 & - & - & - \\
B233 & 15 & 38.6 & + & + & + \\
B262 & 17 & 41.1 & - & - & - \\
\hline & & & & & + \\
\hline
\end{tabular}

Trichogaster and Xiphophorus, were megalocytivirus TaqMan qPCR-positive, with $C_{\mathrm{T}}$ values ranging from 24 to 43 (Table 4). Despite the megalocytivirus nested PCR being the most sensitive of the conventional PCRs tested, the $128 \mathrm{bp}$ amplicon (after primer trimming) limited its usefulness in sequence analysis, as well as the production of non-specific amplicons. In an attempt to generate an amplicon to sequence and confirm the real-time results of samples with high $C_{\mathrm{T}}$ values, a modification of the OIE RSIV/ISKNV PCR was trialed using a $5 \mu$ template
Table 4. ISKNV detected in imported ornamental fish. Megalocytivirus sequence determined from OIE ISKNV/ RSIV 60 cycle PCR amplicons. ND: not determined. Values shown are cycle threshold numbers

\begin{tabular}{|lccc|}
\hline Sample & Host genus & $\begin{array}{c}\text { Megalo- } \\
\text { cytivirus } \\
\text { TaqMan qPCR }\end{array}$ & $\begin{array}{c}\text { Megalo- } \\
\text { cytivirus } \\
\text { sequence }\end{array}$ \\
\hline C4 & Xiphophorus & 43.0 & ND \\
C10 & Trichogaster & 40.1 & ND \\
C39 & Xiphophorus & 39.4 & ND \\
C66 & Trichogaster & 37.0 & ISKNV \\
C67 & Trichogaster & 36.1 & ND \\
C68 & Trichogaster & 36.6 & ISKNV \\
C133 & Pterophyllum & 41.2 & ND \\
C134 & Pterophyllum & 38.3 & ISKNV \\
C135 & Pterophyllum & 35.8 & ND \\
C137 & Pterophyllum & 29.7 & ISKNV \\
C138 & Pterophyllum & 38.7 & ND \\
C139 & Pterophyllum & 38.5 & ND \\
C163 & Poecilia & 39.1 & ISKNV \\
C204 & Xiphophorus & 37.9 & ISKNV \\
C207 & Colisa & 24.0 & ISKNV \\
C208 & Colisa & 35.3 & ND \\
C222 & Pterophyllum & 26.9 & ISKNV \\
C223 & Pterophyllum & 40.4 & ND \\
C224 & Pterophyllum & 40.2 & ND \\
\hline
\end{tabular}

volume in a $50 \mu \mathrm{l}$ reaction volume and 60 cycles of amplification. This approach more consistently yielded amplicons of the expected size for samples with $C_{\mathrm{T}}$ values $>35$. All of the sequences from these amplicons were either identical, or had 1 nucleotide difference, to the reference ISKNV (data not shown).

\section{DISCUSSION}

Megalocytiviruses have not been detected in wild populations of fish in Australia, but ISKNV-like viruses have been detected in imported ornamental fish. In addition, importation of live ornamental fish has been suspected as the source of disease at a Victorian Murray cod farm (Go et al. 2006). Despite Australia's stringent import conditions and quarantine measures, results presented here confirmed that platys at an Australian ornamental fish farm (post quarantine) were infected with ISKNV. It remains unknown how the platys became infected on the farm, but imported platys or other ornamental fish are the most likely source of the virus. Surveillance from 2011 to 2013 (Becker et al. 2013, Nolan et al. 2015) and that described here, from 2013 to 2014, has further confirmed that ISKNV-like viruses are being imported into Australia through the ornamental fish trade. 
Sequence analysis of 3 separate gene regions of the virus detected at the domestic fish farm revealed only 1 nucleotide difference when compared with ISKNV across $>2680$ nucleotides, and therefore, within each region, this virus consistently grouped with the ISKNV phylogenetic cluster of viruses. The virus from the farm was initially identified by Becker et al. (2013) as DGIV; however, the only DGIV sequence (AY989904) available in GenBank is identical to the ISKNV reference (AF371960) over the diagnostic IRB6 region (OIE RSIV/ISKNV PCR). As a consequence, all of the viruses that were identified in the current study have been named ISKNV, to reflect megalocytivirus phylogenetic clustering.

The OIE Manual of Diagnostic Tests for Aquatic Animals (OIE 2014b) has a chapter on RSIVD that describes diagnostic methods for the detection and identification of RSIV and ISKNV. The conventional OIE RSIV/ISKNV PCR in combination with sequencing is currently the molecular detection assay recommended for presumptive and confirmatory diagnosis of RSIVD. TaqMan real-time PCR assays are commonly utilised in diagnostic laboratories to provide rapid, highly sensitive and sequence-specific results. Universal megalocytivirus SYBR Green qPCRs have previously been developed by Caipang et al. (2003), Gias et al. (2011) and Rimmer et al. (2012), but, while more expensive, TaqMan qPCRs are generally more specific and reproducible than SYBR Green assays (Gunson et al. 2006, Beld et al. 2007, Purcell et al. 2011).

Accordingly, we recommend that the megalocytivirus TaqMan qPCR detailed here be added to the RSIVD chapter of the OIE Manual of Diagnostic Tests for Aquatic Animals, to enhance the diagnostic capabilities described therein. Despite its initial design as an RSIV detection assay, we have demonstrated in the current study that it can also detect ISKNV. An analysis of more than 100 GenBank RSIV, ISKNV and TRBIV MCP sequences that contain the primer and probe targets demonstrated that currently no more than 2 mismatches exist. We therefore conclude that the megalocytivirus TaqMan qPCR has significant utility as a universal megalocytivirus diagnostic screening assay.

Acknowledgements. We thank QDAFF and AGDoA staff who collected all specimens analysed. The contribution of the CSIRO AAHL Sequencing Laboratory is also acknowledged. This study was supported by funding from the FRDC on behalf of the Australian Government (FRDC Project 2003/620 Aquatic Animal Health Subprogram: Establishment of Diagnostic Expertise for Detection and Identification of Red Sea Bream Iridovirus [RSIV]).

\section{LITERATURE CITED}

Becker J, Rimmer A, Tweedie A, Landos M, Lintermans M, Whittington R (2013) Aquatic animal health subprogram: surveys of ornamental fish for pathogens of quarantine significance. Project Number 2009/044. Fisheries Research and Development Corporation, Canberra

Beld MGHM, Birch CJ, Cane PA, Carman W and others (2007) Experts roundtable: real-time PCR and microbiology. In: Mackey IM (ed) Real-time PCR in microbiology: from diagnosis to characterization. Caister Academic Press, Norwich, p 357-443

Caipang CM, Hirono I, Aoki T (2003) Development of a realtime PCR assay for the detection and quantification of red seabream iridovirus (RSIV). Fish Pathol 38:1-7

Crane MStJ, Davies KR (2006) Aquatic animal health subprogram: establishment of diagnostic expertise for detection and identification of red sea bream iridovirus (RSIV). Project number 2003/620. Fisheries Research and Development Corporation, Canberra

Gias E, Johnston C, Keeling S, Spence RP, McDonald WL (2011) Development of real-time PCR assays for detection of megalocytiviruses in imported ornamental fish. J Fish Dis 34:609-618

Go J, Lancaster M, Deece K, Dhungyel O, Whittington R (2006) The molecular epidemiology of iridovirus in Murray cod (Maccullochella peelii peelii) and dwarf gourami (Colisa lalia) from distant biogeographical regions suggests a link between trade in ornamental fish and emerging iridoviral diseases. Mol Cell Probes 20:212-222

Gunson RN, Collins TC, Carman WF (2006) Practical experience of high throughput real-time PCR in routine diagnostic virology. J Clin Virol 35:355-367

Jancovich LK, Chinchar VG, Hyatt A, Miyakazi T, Williams T, Zhang QY (2012) Family Iridoviridae. In: King AMQ, Adams MJ, Carstens EB, Lefkowitz EJ (eds) Virus taxonomy. Ninth Report of the International Committee on Taxonomy of Viruses. Elsevier Academic Press, Sydney, p 193-210

Jeong JB, Kim HY, Jun LJ, Lyu JH, Park NG, Kim JK, Jeong HD (2008) Outbreaks and risks of infectious spleen and kidney necrosis virus diseases in freshwater ornamental fishes. Dis Aquat Org 78:209-215

Kim WS, Oh MJ, Kim JO, Kim D, Jeon CH, Kim JH (2010) Detection of megalocytivirus from imported tropical ornamental fish, paradise fish Macropodus opercularis. Dis Aquat Org 90:235-239

Kurita J, Nakajima K (2012) Megalocytiviruses. Viruses 4: 521-538

> Kurita J, Nakajima K, Hirono I, Aoki T (1998) Polymerase chain reaction (PCR) amplification of DNA of red sea bream iridovirus (RSIV). Fish Pathol 33:17-23

Nolan D, Stephens F, Crockford M, Jones JB, Snow M (2015) Detection and characterization of viruses of the genus Megalocytivirus in ornamental fish imported into an Australian border quarantine premises an emerging risk to national biosecurity. J Fish Dis 38:187-195

OIE (World Organisation for Animal Health) (2014a) Aquatic animal health code (2014). Available at: www.oie.int/ en/international-standard-setting/aquatic-code/accessonline/ (accessed on 5 January 2015)

OIE (2014b) Manual of diagnostic tests for aquatic animals 2014. Available at www.oie.int/en/international-standardsetting/aquatic-manual/access-online/ (accessed on 5 January 2015) 
Purcell MK, Getchell RG, McClure CA, Garver KA (2011) Quantitative polymerase chain reaction (PCR) for detection of aquatic animal pathogens in a diagnostic laboratory setting. J Aquat Anim Health 23:148-161

Rimmer AE, Becker JA, Tweedie A, Whittington RJ (2012) Development of a quantitative polymerase chain reaction (qPCR) assay for the detection of dwarf gourami iridoviruses (DGIV) and other megalocytiviruses and comparison with the Office International des Epizooties (OIE) reference protocol. Aquaculture 358-359: 155-163

Sriwanayos P, Francis-Floyd R, Stidworthy MF, Petty BD, Kelley K, Waltzek TB (2013) Megalocytivirus infection in orbiculate batfish Platax orbicularis. Dis Aquat Org 105: $1-8$

Sudthongkong C, Miyata M, Miyazaki T (2002) Iridovirus disease in two ornamental tropical freshwater fishes: African lampeye and dwarf gourami. Dis Aquat Org 48: 163-173

> Tamura K, Peterson D, Peterson N, Stecher G, Nei M, Kumar S (2011) MEGA5: molecular evolutionary genetics analysis using maximum likelihood, evolutionary, distance, and maximum parsimony methods. Mol Biol Evol 28: 2731-2739

Weber ES, Waltzek TB, Young DA, Twitchell EL and others (2009) Systemic iridovirus infection in the Banggai cardinalfish (Pterapogon kauderni Koumans 1933). J Vet Diagn Invest 21:306-320

Whittington RJ, Chong R (2007) Global trade in ornamental fish from an Australian perspective: the case for revised import risk analysis and management practices. Prev Vet Med 81:92-116

Appendix. Amplicon sequences submitted to GenBank. -: not sequenced

\begin{tabular}{|lccc|}
\hline Sample & $\begin{array}{c}\text { OIE RSIV/ } \\
\text { ISKNV PCR }\end{array}$ & $\begin{array}{c}\text { RSIV/ISKNV/ } \\
\text { TRBIV PCR }\end{array}$ & $\begin{array}{c}\text { ATPase } \\
\text { PCR }\end{array}$ \\
\hline A2 & KP292943 & KP292956 & KP292961 \\
B23 & KP292944 & KP292957 & KP292962 \\
B152 & KP292945 & KP292958 & KP292963 \\
B182 & KP292946 & KP292959 & KP292964 \\
B221 & KP292947 & KP292960 & KP292965 \\
C66 & KP292948 & - & - \\
C68 & KP292949 & - & - \\
C134 & KP292950 & - & - \\
C137 & KP292951 & - & - \\
C163 & KP292952 & - & - \\
C204 & KP292953 & - & - \\
C207 & KP292954 & - & \\
C222 & KP292955 & - & \\
a & & & \\
\hline
\end{tabular}

Editorial responsibility: Catherine Collins, Aberdeen, UK
Submitted: February 4, 2015; Accepted: June 18, 2015

Proofs received from author(s): September 18, 2015 